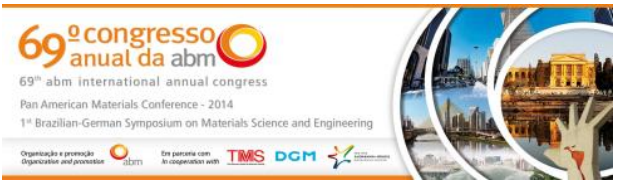

Tema: Tratamento Térmico

\title{
INLUÊNCIA DAS DEFORMAÇÕES MONOTÔNICA E CÍCLICA NO COMPORTAMENTO MECÂNICO DE UMA LIGA DE ALUMÍNIO SUBMETIDA A ENDURECIMENTO POR PRECIPITAÇÃO*
}

\author{
Tâmisa Eleutério Silva ${ }^{1}$ \\ Natasha Nogueira² \\ Wellington Lopes ${ }^{3}$ \\ Joel Romano Brandão 4 \\ Elaine Carballo Siqueira Corrêa ${ }^{5}$
}

\section{Resumo}

Ligas de alumínio possuem, dentre diversas propriedades, uma atrativa combinação entre resistência mecânica e densidade, característica que leva à utilização cada vez maior desses materiais em setores estratégicos, como as indústrias aeronáutica e automobilística. O aumento da resistência dessas ligas, por sua vez, está associado ao tratamento de endurecimento por precipitação, podendo ainda ser influenciado pelo encruamemto do metal, esse último decorrente da eventual realização de deformação plástica entre as etapas de solubilização e envelhecimento do referido processamento. Dentro desse contexto, neste trabalho foi avaliado o comportamento mecânico de amostras da liga de alumínio 7.075 submetidas à compressão monotônica e cíclica após a etapa de solubilização do tratamento de endurecimento por precipitação. O comportamento do material foi analisado através de ensaios de dureza. Os resultados evidenciaram os efeitos das características e da magnitude da deformação na propriedade mecânica da liga.

Palavras-chave: Deformação; Endurecimento por precipitação; Liga de alumínio.

\section{INFLUENCE OF MONOTONIC AND CYCLIC STRAIN ON THE MECHANICAL BEHAVIOR OF AN ALUMINUM ALLOY SUBMITTED TO PRECIPITATION HARDENING HEAT TREATMENT}

\begin{abstract}
Aluminum alloys have, among several properties, an attractive combination of strength and density, which leads to an increased use of these materials in strategic sectors, such as aeronautical and automotive industries. The significant increase of strength in these alloys is usually associated with the precipitation hardening heat treatment, and may also be influenced by work hardening, the latter resulting from plastic deformation between the solution treatment and aging. In his study the mechanical behavior of 7075 aluminum alloy samples subjected to monotonic and cyclic compression after solution treatment was evaluated. The behavior of the material was analyzed through hardness tests. The results showed the effects of the characteristics and the magnitude of the strain in the mechanical property of the aluminum alloy.
\end{abstract}

Keywords: Deformation; Precipitation hardening; Aluminum alloy.

Eng. Materiais, Mestranda Eng. Materiais, CEFET-MG, Belo Horizonte, MG, Brasil

Eng. Materiais, NEMAK Alumínio do Brasil, Belo Horizonte, MG, Brasil

Eng. Mecânico, Dr., Professor, Depto. Eng. Materiais, CEFET-MG, Belo Horizonte, MG, Brasil

MSc., Professor, Depto. Eng. Materiais, CEFET-MG, Belo Horizonte, MG, Brasil

Eng. Mecânica, Dra., Professora, Depto. Eng. Materiais, CEFET-MG, Belo Horizonte, MG, Brasil.

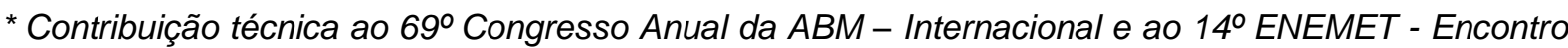
Nacional de Estudantes de Engenharia Metalúrgica, de Materiais e de Minas, 21 a 25 de julho de 2014, São Paulo, SP, Brasil. 


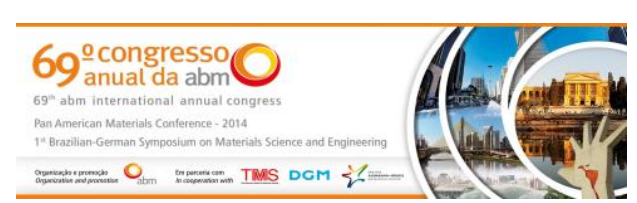

\section{INTRODUÇÃO}

A utilização de ligas de alumínio nas indústrias aeronáutica e automobilística vem crescendo a cada dia devido a diversos fatores, dentre os quais se destaca a relação entre a sua resistência mecânica e a densidade. A resistência mecânica desses materiais é, de maneira geral, obtida por meio do emprego do tratamento térmico de endurecimento por precipitação, que envolve etapas de solubilização seguida de resfriamento brusco e envelhecimento. Esse processamento térmico é caracterizado pela formação de partículas finas e dispersas de uma segunda fase em uma matriz de outra fase cristalina, sendo o endurecimento do metal associado à interação das discordâncias com os precipitados mencionados [1,2]. Diversos fatores podem alterar o comportamento mecânico da liga ao final desse tratamento, especialmente a temperatura e o tempo de envelhecimento. Em adição a esses parâmetros, a realização de deformação plástica a frio entre as etapas do tratamento térmico, ou seja, entre a solubilização e o envelhecimento, também é capaz de afetar suas propriedades, fato relacionado à ocorrência de encruamento do material. O encruamento, fenômeno que consiste no aumento contínuo da tensão cisalhante à medida que a deformação plástica é conduzida [2], é uma das principais características dos metais durante a conformação mecânica a frio. Embora os efeitos relacionados ao mesmo possam ser observados em diversas propriedades físicas, as alterações produzidas pela deformação plástica se referem, sobretudo, às propriedades mecânicas do material, como o aumento da resistência mecânica e a redução da ductilidade. Dessa forma, além de ser um aspecto típico do processamento dos metais, representa um dos mais importantes métodos industriais para endurecer os mesmos [2,3].

No entanto, sob condições de processamento específicas, associadas a alterações na direção/sentido da deformação plástica ou a aplicação de deformação cíclica, a elevação contínua da resistência mecânica típica do encruamento, dentre outros fenômenos, pode não ser observada. Trata-se do chamado efeito do caminho de deformação no comportamento mecânico dos materiais, cujos resultados podem envolver ocorrência de um estado de tensões constante, encruamento mais acentuado ou o oposto em virtude de alterações na taxa de encruamento e, até mesmo, amaciamento do metal pré-deformado devido ao emprego de deformação plástica subsequente [4-11].

Dentro deste contexto, neste trabalho foram avaliados os efeitos da aplicação de deformação plástica a frio por compressão entre as etapas de solubilização e envelhecimento do tratamento térmico de endurecimento por precipitação da liga de alumínio 7075 , considerando tanto a aplicação de deformação monotônica como de deformação cíclica.

\section{MATERIAIS E MÉTODOS}

\subsection{Materiais}

Para a realização do estudo foi utilizada a liga de alumínio aeronáutico 7075 , adquirida na forma de chapas com espessura de $5,7 \mathrm{~mm}$. Esse material apresenta-se como uma liga alumínio-zinco-magnésio, cuja composição química (\% em peso) é exibida na Tabela 1.

\footnotetext{
* Contribuição técnica ao $69^{\circ}$ Congresso Anual da ABM - Internacional e ao 14ํㅡㄹ ENEMET - Encontro Nacional de Estudantes de Engenharia Metalúrgica, de Materiais e de Minas, 21 a 25 de julho de 2014, São Paulo, SP, Brasil.
} 


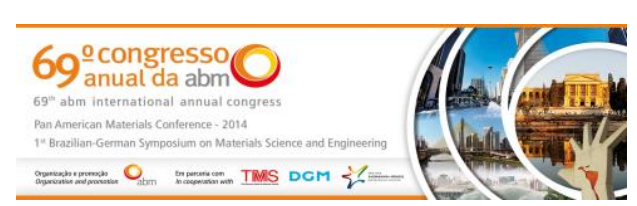

Tabela 1. Composição química (\% em peso) da liga de alumínio 7075

\begin{tabular}{cccccccc}
\hline Elemento & $\mathrm{Cr}$ & $\mathrm{Cu}$ & $\mathrm{Mg}$ & $\mathrm{Zn}$ & $\mathrm{Ti}$ & $\mathrm{Fe}$ & $\mathrm{Si}$ \\
\hline$\%$ & 0,2 & 1,8 & 2,2 & 6,0 & 0,004 & 0,07 & 0,03 \\
\hline
\end{tabular}

\subsection{Corpos de Prova}

Os corpos de prova foram confeccionados por eletroerosão a fio, com formato cúbico, ser adequado à compressão, com aresta de $5,7 \mathrm{~mm}$, cuja representação esquemática é mostrada na Figura 1.

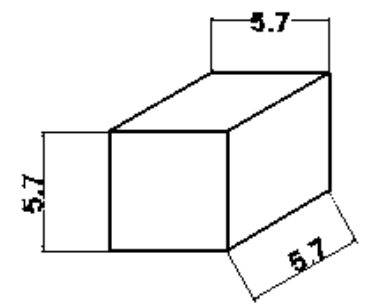

Figura 1. Representação esquemática do corpo de prova (dimensões em mm).

\subsection{Tratamentos Térmicos}

Os tratamentos térmicos conduzidos foram o recozimento e o endurecimento por precipitação, este último composto das etapas de solubilização seguida de resfriamento brusco e envelhecimento.

$\mathrm{Na}$ Tabela 2 podem ser observados os parâmetros de recozimento (temperatura e tempo) empregados. Verifica-se que os mesmos foram determinados a partir de consulta à bibliografia [12] e posterior verificação dos resultados através de ensaios de dureza. Todas as amostras foram submetidas ao recozimento, de forma que esse passou a ser considerado o estado inicial do material para realização de todo o trabalho.

Tabela 2. Parâmetros de recozimento empregados no trabalho

\begin{tabular}{cc}
\hline Temperatura & Tempo \\
\hline $420^{\circ} \mathrm{C}$ & $60 \mathrm{~min}$ \\
\hline
\end{tabular}

Os tratamentos de endurecimento por precipitação foram realizados conforme as condições exibidas na Tabela 3. De maneira análoga aos parâmetros de recozimento, os dados apresentados foram escolhidos com base na literatura [12]. Neste caso, pode ser destacado o fato de que algumas amostras previamente recozidas foram submetidas ao tratamento de endurecimento por precipitação de maneira direta, ou seja, a solubilização foi seguida de envelhecimento, enquanto outras amostras foram solubilizadas, deformadas e então envelhecidas. Por fim, ressalta-se que os corpos de prova solubilizados, antes de serem submetidos à deformação e/ou ao envelhecimento, foram mantidos a uma temperatura de aproximadamente $0^{\circ} \mathrm{C}$.

Tanto os tratamentos de recozimento como de endurecimento por precipitação foram conduzidos em um forno elétrico da marca Brasimet.

\footnotetext{
* Contribuição técnica ao 69ำ Congresso Anual da ABM - Internacional e ao 14ํㅡㄹ ENEMET - Encontro Nacional de Estudantes de Engenharia Metalúrgica, de Materiais e de Minas, 21 a 25 de julho de 2014, São Paulo, SP, Brasil.
} 


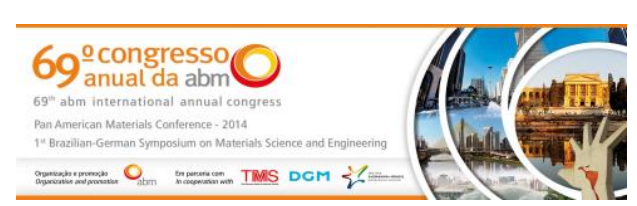

Tabela 3. Parâmetros de endurecimento por precipitação empregados no trabalho

\begin{tabular}{cccc}
\hline Solubilização - & Temperatura & Tempo & Resfriamento \\
parâmetros & $480^{\circ} \mathrm{C}$ & $60 \mathrm{~min}$ & Água \\
\hline Envelhecimento - & Temperatura & Tempo & Resfriamento \\
parâmetros & $120^{\circ} \mathrm{C}$ & $24 \mathrm{~h}$ & Água \\
\hline
\end{tabular}

\subsection{Deformação}

Corpos de prova recozidos e posteriormente solubilizados foram deformados a frio monotonica e ciclicamente por meio de compressão empregando uma prensa hidráulica da marca Manley.

Em termos de deformação convencional monotônica, foram consideradas quatro magnitudes: 5\%, 10\%; 15\% e 30\%. Considerando a deformação cíclica, foram estabelecidas três condições. A primeira correspondeu à aplicação de deformação de $5 \%$ em cada eixo do corpo de prova $(5 \% A B C)$, a segunda correspondeu à aplicação de uma deformação de $10 \%$ em cada eixo (10\% ABC) e a terceira correspondeu à deformação de $5 \%$ em cada eixo da amostra seguida por uma nova sequência de deformação de $5 \%$ (5\% ABC ABC). Na Figura 2 pode ser verificada a representação esquemática das sequências de deformação cíclica conduzidas.

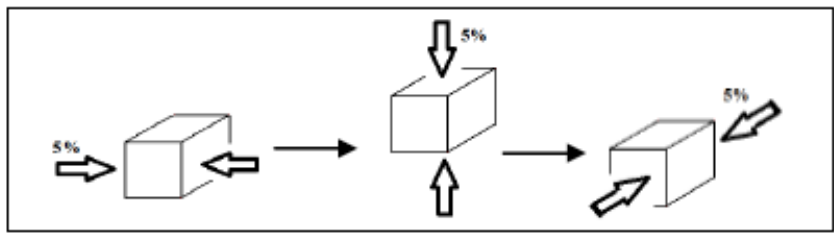

(a)

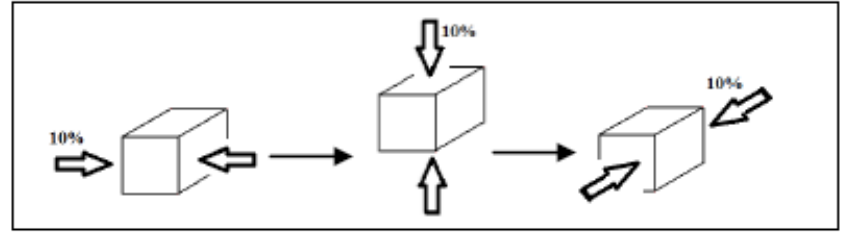

(b)

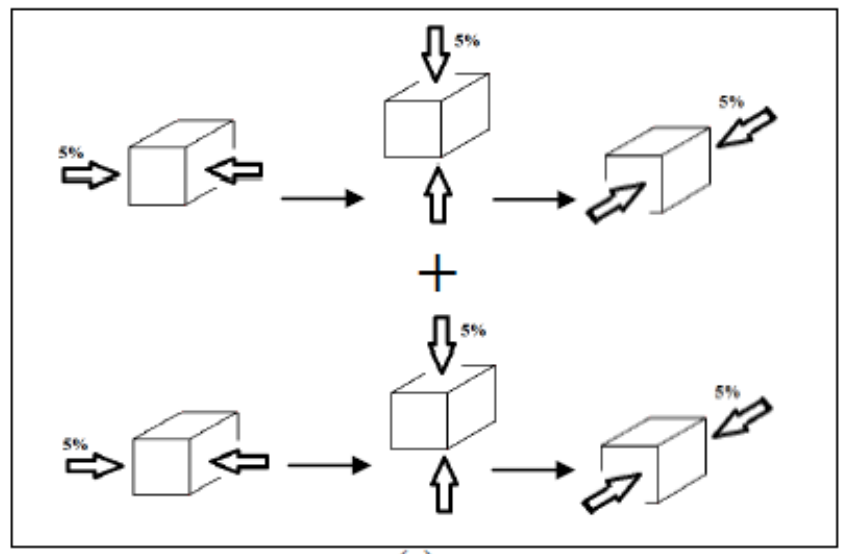

(c)

Figura 2. Representação esquemática da deformação cíclica nos corpos de prova: (a) deformação de $5 \%$ em cada eixo, (b) deformação de $10 \%$ em cada eixo e (c) deformação de $5 \%$ em cada eixo seguida de sequência similar.

\footnotetext{
* Contribuição técnica ao 69 Congresso Anual da ABM - Internacional e ao 14ํㅡㄹ ENEMET - Encontro Nacional de Estudantes de Engenharia Metalúrgica, de Materiais e de Minas, 21 a 25 de julho de 2014, São Paulo, SP, Brasil.
} 


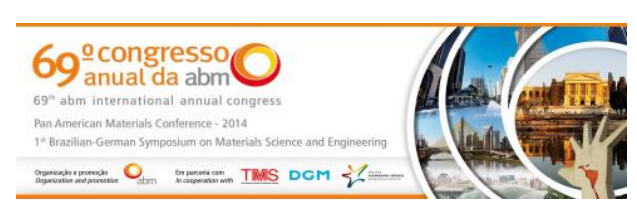

\subsection{Ensaios de Dureza}

Os ensaios da dureza Vickers foram realizados em um microdurômetro marca Shimadzu modelo HMV 2T. Foram empregadas ao menos três amostras para cada condição, tendo sido realizados 6 testes em cada, com carga de 0,3kgf e tempo de aplicação de 15s.

\section{RESULTADOS E DISCUSSÃO}

Os resultados de dureza Vickers da liga de alumínio 7075 nos estados recozido, solubilizado e solubilizado e envelhecido são mostrados na Tabela 4. Percebe-se coerência dos valores encontrados com os tratamentos realizados, uma vez que o material recozido apresenta menor dureza, o solubilizado dureza intermediária e o envelhecido maior dureza.

Tabela 4. Dureza média do material nas condições recozido, solubilizado/resfriado e solubilizado/resfriado e envelhecido

\begin{tabular}{cc}
\hline Tratamento Térmico & Dureza HV \\
\hline Recozido & 64 \\
Solubilizado & 136 \\
Solubilizado e envelhecido & 164 \\
\hline
\end{tabular}

$\mathrm{Na}$ Tabela 5 podem ser observados os dados da dureza média do alumínio solubilizado e deformado monotonicamente em diferentes magnitudes. Assim como esperado, devido ao fenômeno de encruamento, a amostra submetida à menor deformação apresenta a menor dureza, que aumenta com magnitude da deformação.

Tabela 5. Dureza média do material depois solubilizado e deformado monotonicamente

\begin{tabular}{cc}
\hline Deformação & Dureza HV \\
\hline $5 \%$ & 138 \\
$10 \%$ & 149 \\
$15 \%$ & 156 \\
$30 \%$ & 162 \\
\hline
\end{tabular}

As durezas médias das amostras da liga de alumínio solubilizadas e deformadas ciclicamente são apresentadas a seguir (Tabela 6). Conforme pode ser observado, 0 material submetido à deformação cíclica de $5 \%$ em cada um dos eixos possui a dureza média superior ao material submetido a duas sequências de deformação cíclica de 5\% em cada um dos eixos. Comparando as amostras deformadas ciclicamente de $5 \%$ em cada um dos eixos (somente uma vez em cada direção) e as amostras deformadas ciclicamente de $10 \%$ em cada um dos eixos é possível perceber que não há alteração na dureza média, ou seja, o aumento na amplitude de deformação cíclica neste caso não levou à elevação de dureza do material.

\footnotetext{
* Contribuição técnica ao $69^{\circ}$ Congresso Anual da ABM - Internacional e ao 14ํㅡㄹ ENEMET - Encontro Nacional de Estudantes de Engenharia Metalúrgica, de Materiais e de Minas, 21 a 25 de julho de 2014, São Paulo, SP, Brasil.
} 


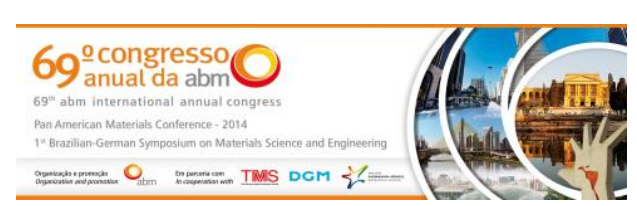

Tabela 6. Dureza média do material solubilizado e deformado ciclicamente

\begin{tabular}{cc}
\hline Deformação & Dureza HV \\
\hline $5 \%$ ABC & 157 \\
$5 \% A B C A B C$ & 147 \\
$10 \% A B C$ & 157 \\
\hline
\end{tabular}

Comparando as durezas apresentadas pelos corpos de prova deformados monotonica e ciclicamente verifica-se que, ao submeter o material a uma deformação total de $15 \%$, seja ela monotônica ou cíclica ( $5 \% A B C)$, o valor de dureza praticamente não foi alterado, ou seja, ambas as deformações monotônica e cíclica promoveram o mesmo aumento de dureza no material solubilizado (Figura 3).

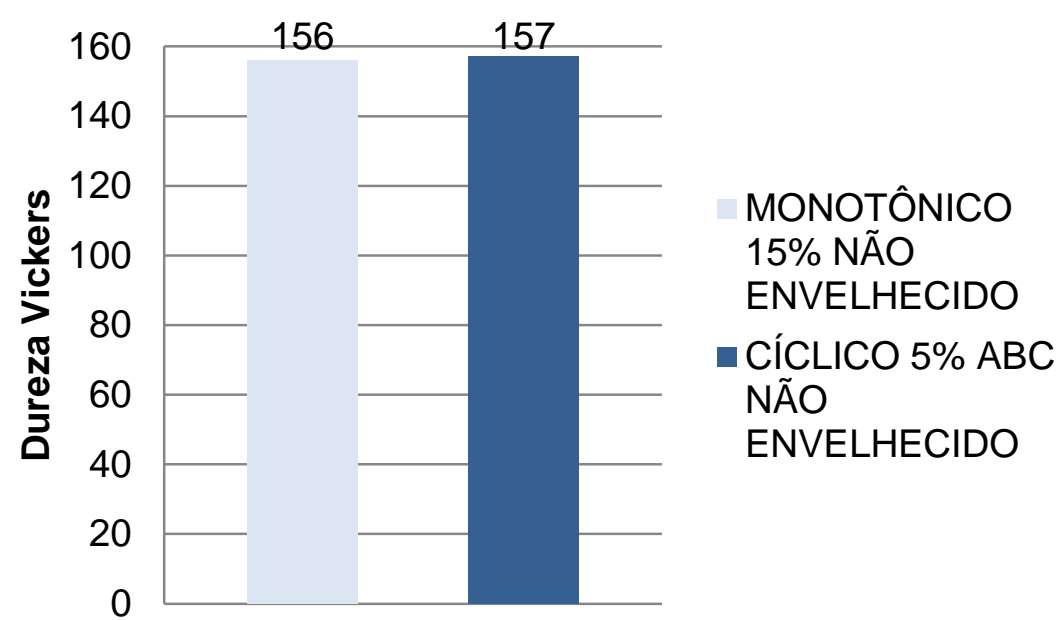

Figura 3. Comparação entre a dureza do material solubilizado deformado de $15 \%$ monotonicamente e o material solubilizado deformado $15 \%$ ciclicamente $(5 \% A B C)$.

Por outro lado, é possível perceber diferença na propriedade mecânica da liga de alumínio 7075 recozida e solubilizada ao comparar as amostras submetidas à deformação monotônica de $30 \%$ com aquelas submetidas à deformação cíclica total de $30 \%$, ou seja, as amostras deformadas $5 \%$ em cada um dos eixos em duas seqüências (5\% ABC $A B C)$ e as amostras deformadas $10 \%$ em cada um dos eixos (10\% ABC), conforme a Figura 4. O material deformado monotonicamente apresenta dureza superior às demais amostras, especialmente em relação à peça da seqüência $5 \% A B C A B C$. Essa amostra também exibe valor inferior à outra deformada ciclicamente 10\% ABC e ainda à deformada $5 \%$ ABC (Figura 3). Este fato sugere que a segunda sequência de deformação cíclica de $5 \%$ em cada eixo amaciaria 0 material previamente deformado, remetendo aos trabalhos apresentados na literatura $[4,9,10]$. Em relação à liga de alumínio deformada monotonicamente de $30 \%$ e ao material deformado ciclicamente $10 \%$ em cada um dos eixos (10\% $A B C)$, a constatação que pode ser feita é que a deformação cíclica, embora encrue o material, parece ter efeito menos significativo que o provocado pela deformação monotônica [4,5,7-9].

\footnotetext{
* Contribuição técnica ao 69ำ Congresso Anual da ABM - Internacional e ao 14ํㅡㄹ ENEMET - Encontro Nacional de Estudantes de Engenharia Metalúrgica, de Materiais e de Minas, 21 a 25 de julho de 2014, São Paulo, SP, Brasil.
} 

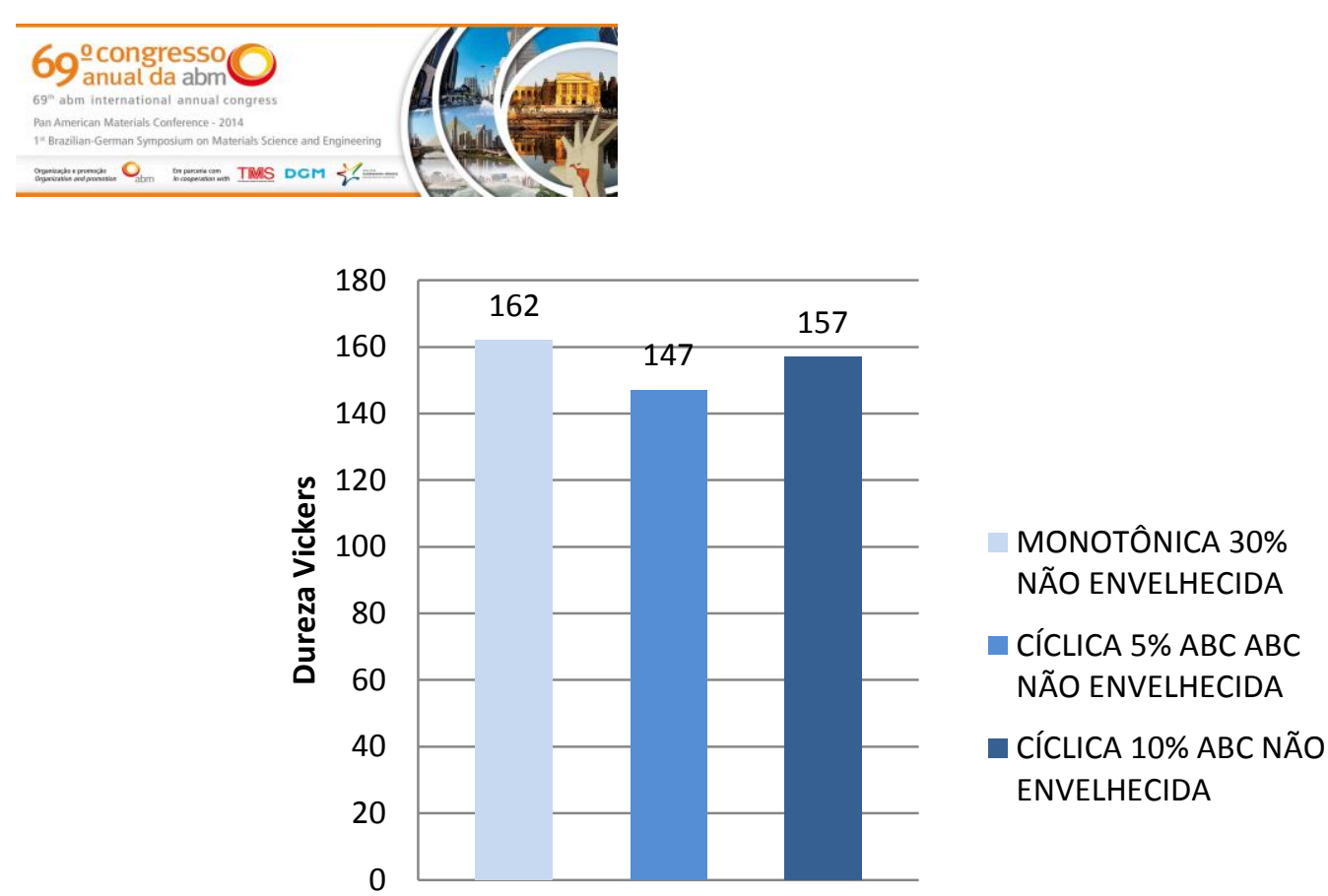

Figura 4. Comparação entre a dureza do material solubilizado deformado $30 \%$ monotonicamente e o material solubilizado deformado $30 \%$ ciclicamente (5\% ABC ABC e $10 \% A B C)$.

A dureza média dos corpos de prova solubilizados, deformados monotonicamente e envelhecidos é exibida na Tabela 7. Observa-se que o material que sofreu deformação monotônica de $5 \%$ antes do envelhecimento é o que apresenta maior valor de dureza, sendo que entre os demais a diferença não é significativa. Esses resultados contrastam com aqueles verificados na liga de alumínio não envelhecida.

Tabela 7. Dureza média do material solubilizado, deformado monotonicamente e envelhecido

\begin{tabular}{cc}
\hline Deformação (\%) & Dureza \\
\hline 5 & 180 \\
10 & 166 \\
15 & 168 \\
30 & 170 \\
\hline
\end{tabular}

Considerando os valores de dureza média apresentados pelas amostras solubilizadas e deformadas monotonicamente, não envelhecidas e envelhecidas, exibidos na Figura 5, percebe-se que quanto menor a magnitude de deformação monotônica, maior parece ser o efeito do envelhecimento na liga de alumínio.

$\mathrm{Na}$ Tabela 8 são fornecidos os valores de dureza média das amostras solubilizadas, deformadas ciclicamente e envelhecidas. Assim como no material submetido à deformação monotônica entre as etapas de solubilização e envelhecimento, as amostras deformadas a uma magnitude menor entre essas mesmas duas etapas foram as que apresentaram maior dureza, ou seja, as amostras submetidas à deformação cíclica de $5 \%$ em cada um dos eixos foram as que apresentaram a maior dureza. Ao comparar o resultado do material solubilizado deformado na sequência $5 \% \mathrm{ABC}$ e envelhecido com 0 valor apresentado pelo material solubilizado, deformado na sequência $5 \% A B C A B C$ e depois envelhecido constatase novamente que a segunda sequência de deformação amaciaria a liga em relação à primeira sequência de deformação.

\footnotetext{
* Contribuição técnica ao 69ำ Congresso Anual da ABM - Internacional e ao 14ํㅡㄹ ENEMET - Encontro Nacional de Estudantes de Engenharia Metalúrgica, de Materiais e de Minas, 21 a 25 de julho de 2014, São Paulo, SP, Brasil.
} 


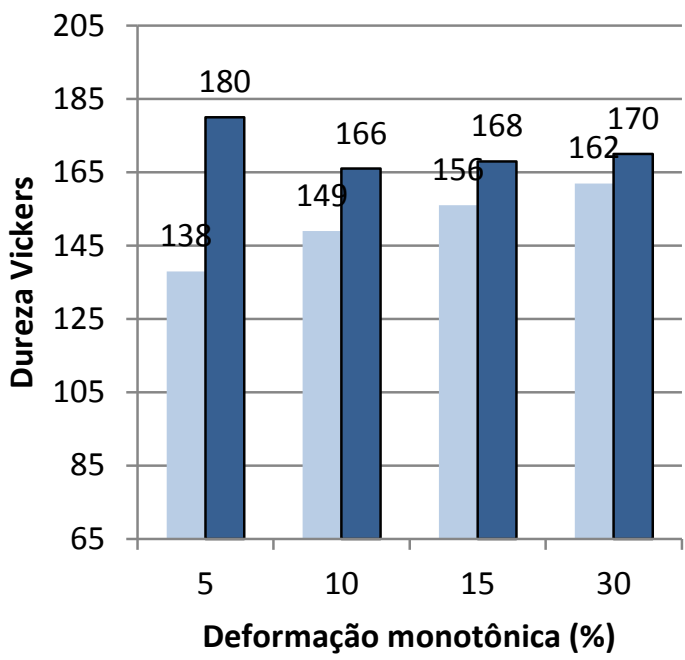

MONOTONNICO NÃO ENVELHECIDO

$\square$ MONOTÔNICO ENVELHECIDO

Figura 5. Efeito do envelhecimento na dureza do material solubilizado e deformado monotonicamente em diferentes magnitudes.

Tabela 8. Dureza média do material solubilizado e deformado ciclicamente e envelhecido

\begin{tabular}{cc}
\hline Deformação & Dureza \\
\hline $5 \% \mathrm{ABC}$ & 174 \\
$5 \% \mathrm{ABC} A B C$ & 154 \\
$10 \% \mathrm{ABC}$ & 169 \\
\hline
\end{tabular}

Fonte: Produzido pelo Autor.

Considerando as amostras solubilizadas e deformadas ciclicamente, envelhecidas e não envelhecidas, cujos resultados são representados na Figura 6, observa-se que a condição que levou ao maior aumento de dureza foi aquela na qual o material foi deformado ciclicamente $5 \%$ em cada um dos eixos antes do envelhecimento $(5 \%$ $A B C)$.

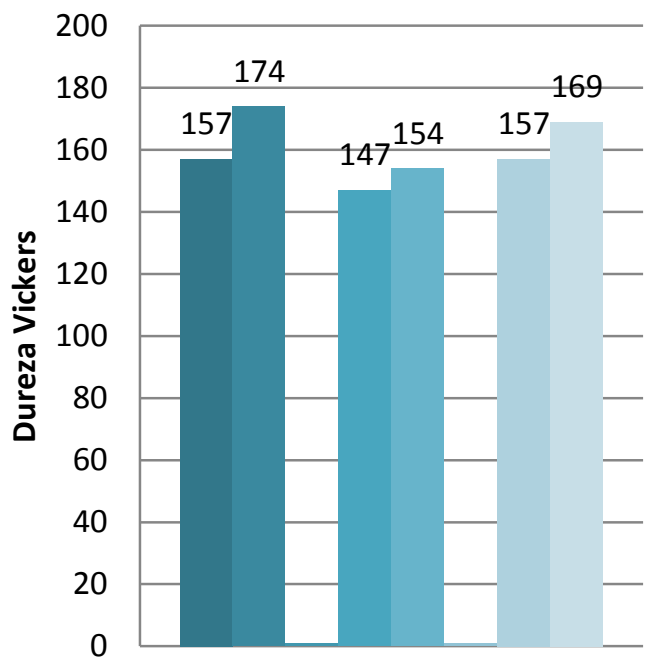

- CÍCLICA 5\% ABC NÃO ENVELHECIDA

- CÍCLICA 5\% ABC ENVELHECIDA

- CÍCLICA 5\% ABC ABC NÃO ENVELHECIDA

- CÍCLICA 5\% ABC ABC

ENVELHECIDA

- CÍCLICA 10\% ABC NÃO

ENVELHECIDA

Figura 6. Efeito do envelhecimento na dureza do material solubilizado e deformado ciclicamernte em diferentes magnitudes.

\footnotetext{
* Contribuição técnica ao 69 Congresso Anual da ABM - Internacional e ao 14ํㅡㄹ ENEMET - Encontro Nacional de Estudantes de Engenharia Metalúrgica, de Materiais e de Minas, 21 a 25 de julho de 2014, São Paulo, SP, Brasil.
} 


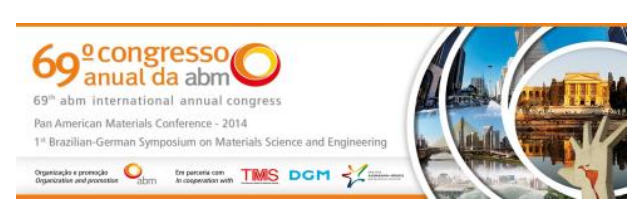

Nas Figuras 7 e 8 podem ser observadas as comparações entre os valores de dureza média das amostras solubilizadas e deformadas monotonicamente de $15 \%$ e $30 \%$ e das amostras solubilizadas e deformadas ciclicamente de $15 \%(5 \% A B C)$ e $30 \%$ (5\% ABC ABC e 10\% ABC), todas envelhecidas e não envelhecidas. Verificase que os menores valores de deformação, em geral, levam aos aumentos mais acentuados de dureza com a realização da etapa de envelhecimento do tratamento de endurecimento por precipitação. Outra constatação obtida por meio desta comparação é que o material deformado ciclicamente, quando submetido a deformações totais de $15 \%$ entre as etapas de solubilização e envelhecimento, tem seu envelhecimento mais eficaz em termos de ganho de dureza do que quando deformado monotonicamente.

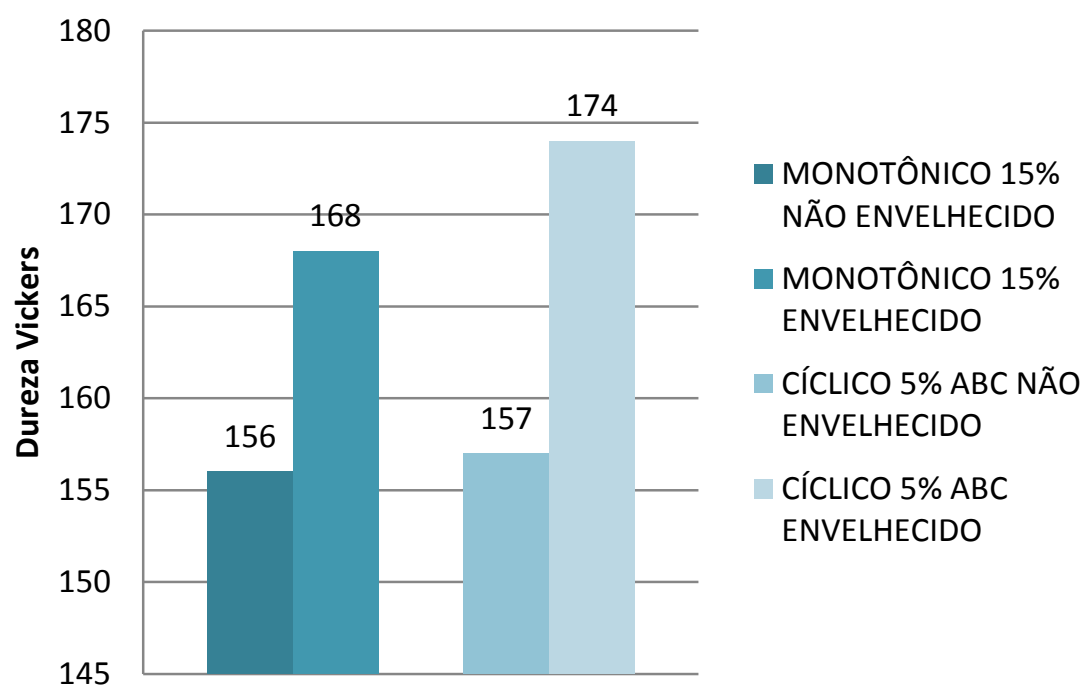

Figura 7. Comparação do efeito da natureza da deformação, com valor total de $15 \%$, na elevação de dureza devida ao envelhecimento.

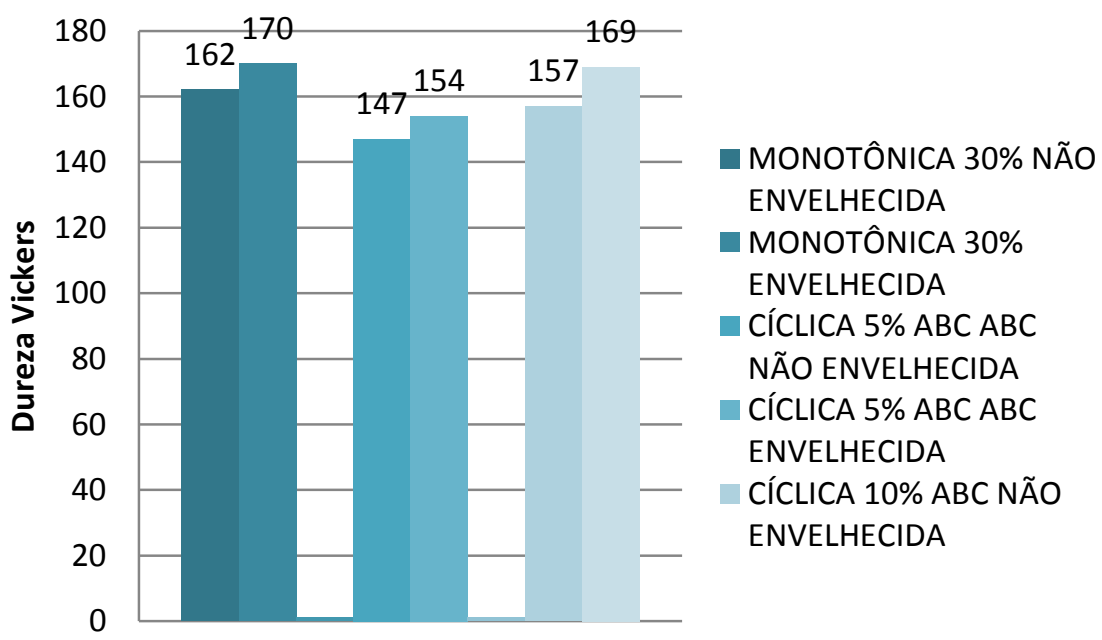

Figura 8. Comparação do efeito da natureza da deformação, com valor total de $30 \%$, na elevação de dureza devida ao envelhecimento.

\footnotetext{
* Contribuição técnica ao $69^{\circ}$ Congresso Anual da ABM - Internacional e ao 14ํㅡㄹ ENEMET - Encontro Nacional de Estudantes de Engenharia Metalúrgica, de Materiais e de Minas, 21 a 25 de julho de 2014, São Paulo, SP, Brasil.
} 


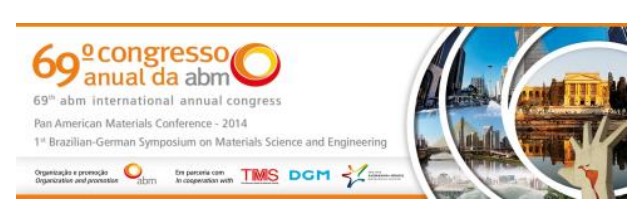

\section{CONCLUSÕES}

As amostras da liga de alumínio 7075 solubilizadas e deformadas monotonicamente apresentaram o comportamento mecânico esperado para materiais deformados a frio, ou seja, se tornaram mais encruadas a medida que a magnitude de deformação foi elevada. Por meio da análise da dureza das amostras solubilizadas e deformadas ciclicamente foi possível perceber que, quando deformadas em duas sequências de deformação, de mesma magnitude, o efeito de caminho de deformação pode ser percebido por meio da redução da dureza em relação ao material submetido apenas a uma sequência de deformação de mesma magnitude.

Considerando a aplicação de deformação tanto monotônica como cíclica, verifica-se que os menores valores de deformação, em geral, levaram aos aumentos mais acentuados de dureza com a etapa de envelhecimento do tratamento de endurecimento por precipitação conduzido no trabalho.

\section{Agradecimentos}

Os autores agradecem à agência de fomento FAPEMIG (Fundação de Amparo á Pesquisa do Estado de Minas Gerais) pelas bolsas de iniciação científica.

\section{REFERÊNCIAS}

1 Reed-Hill RE. Princípios de metalurgia física. 2 ed. Rio de Janeiro: Guanabara Dois; 1982.

2 Dieter GE. Metalurgia mecânica. 2 ed. Rio de Janeiro: Guanabara Dois; 1981.

3 Meyers MA, Chawla KK. Princípios de metalurgia mecânica. São Paulo: Edgard Blucher Ltda.; 1982.

4 Armstrong PE, Hockett JE, Sherby OD. Large strain multidirectional deformation of 1100 aluminum at 300K. Journal of the Mechanics and Physics of Solids; 1982;30:37-58.

5 Subramanyasarma V, Padmanabhan KA. Transmission electron microscopy of a cyclically deformed medium carbon microalloyed steel. Journal of Materials Science Letters. 1997;16:1495-98.

6 Rauch EF, Gracio JJ, Barlat F. Work-hardening model for polycrystalline metals under strain reversal at large strains. Acta Materialia. 2007;55:2939-48.

7 Richert M. The effect of unlimited cumulation of large strains on the structure-softening processes of 99,999Al. Materials Science and Engineering. 1990;A129:1-10.

8 Richert M, Korbel A. The effect of strain localization on mechanical properties of Al99,992 in the range of large deformation. Journal of Materials Processing Technology. 1995;53:331-340.

9 Correa ECS, Aguilar MTP, Silva EMP, Cetlin PR. The effect of sequential tensile and cyclic torsion straining on work hardening of steel and brass. Journal of Materials Processing Technology. 2003;142:282-288.

10 Kowalewski ZL, Szymczak T, Maciejewski J. Material effects during monotonic-cyclic loading. International Journal of Solids and Structures. 2014;51:740-753.

11 Sakharova NA, Fernandes JV. Strain path change effect on dislocation microstructure of multicrystalline copper sheets. Materials Chemistry and Physics. 2006;98:44-50.

12 ASM Handbook. Heat treating. 3 ed. Ohio: American Society for Metals - ASM International; 1995. v.4.

\footnotetext{
* Contribuição técnica ao $69^{\circ}$ Congresso Anual da ABM - Internacional e ao 14ํㅡㄹ ENEMET - Encontro Nacional de Estudantes de Engenharia Metalúrgica, de Materiais e de Minas, 21 a 25 de julho de 2014, São Paulo, SP, Brasil.
} 